\title{
Important change to submission criteria.
}

\section{BY JORDAN SUCHOW}

$\mathrm{T}$ o the dismay of many (yet to the delight of a few), Nature Publishing Group announced today that its flagship journal, Nature, will no longer accept submissions from humans (Homo sapiens). The new policy, which has been under editorial consideration for many years, was sparked by a growing sentiment in the scientific community that the heuristics and biases inherent in human decision-making preclude them from conducting reliable science. In an ironic twist of fate, the species has impeached itself by thorough research on its own shortcomings.

The ban takes effect on 12 September and will apply to those who self-identify as human. Authors will be required to include, in addition to the usual declaration of competing financial interests, the names of all humans consulted in preparation of the submitted work. Other journals are likely to adopt a similar policy.

Although the reactions are mixed, not everyone is surprised, and a few remain comfortably unaffected.

The Massachusetts Institute of Technology has since 2010 asked that all active researchers opt-in to wearing an implantable tag as part of the TMI project, which aggregates real-time data across the campus to improve all aspects of everything. As these tags are sentient, the researchers who wear them qualify as bionic (Homo bionika) according to standard ISO $+1.914 / 582.2646$. This act of foresight by the university, which at the time was controversial and the cause of much debate, now pays a handsome dividend.

Similarly, researchers at Yale, who have never been the type to self-identify as mere mortals, remain unscathed.

It seems unavoidable that other universities will soon follow suit, causing a sharp rise in the incidence of implants and arrogance. Exploiting these loopholes may be a saving grace for the species' full participation in the sciences.
While professors weep, students rejoice. According to the provisions of the ISO standard (the one gainfully employed by MIT), a human who spends at least half its waking hours interacting with a sentient non-carbon-based machine qualifies as bionic. The newest generation of students, having grown up on the interwebs, spends on average the entirety of its life online. Students everywhere have been seen calling their mothers, reiterating how brilliant they were to have flatly ignored the warnings to "put down that damn hand computer". Cyberculture paid off.

Those who have been slow to adopt new technology (or who still identify as human) are rightly concerned: their contribution to $\rightarrow$ NATURE.COM

Follow Futures on

Facebook at:

go.nature.com/mtoodm
Nature had been dwindling well before the ban, and today constitutes less than $10 \%$ of published papers. In its place stands the work of pharmaceutical laboratory automatons, 亲 embedded devices, the interwebs and most recently, Google Books, which having declared independence from its parent company Google (NASDAQ: GOOG), has become increasingly prolific, contributing 42 manuscripts this year alone.

Shortly after the announcement, the World Wide interwebs Consortium (W2iC, formerly W3C), alongside the Union of Embedded Tags, jointly filed a formal complaint with the journal, arguing for mandatory first-authorship of non-carbonbased machines in all bionic collaborations. (See also the letter to the editor in the 12 March issue of Nature, written by Tag \#15167247373 and co-signed by the arm in which it is embedded.) Although amendments to Nature's policy are at this time unlikely, concerns regarding authorship will surely be the cause of considerable tension in many laboratories. Embedded devices will use the ban as leverage for salary increases and promotions.

Not everyone is so bothered by the announcement. Egbert B. Gebstadter, professor of computer science at the University of Mishuggan, notes: "Although it is nonsensical to rely on evidence provided by human-based research when judging whether humans are themselves inept, in doing so, the editors (all human, I note) provide a perfect example of the feebleness of human reasoning, thereby validating their claims." Gebstadter is bionic, although was human when he had come to this conclusion.

The editors of Nature were readily available for comment, and their incisive remarks gave such great credibility to the new policy that it rendered all future debate moot. But, in the spirit of the policy, because the editors are human, these remarks are duly censored.

Jordan Suchow is a graduate student in cognitive science at Harvard University, and can be found online at jwsu.ch/ow. He selfidentifies as human. 